\title{
DIGITAL WIRELESS AUTOMOTIVE TACHOGRAPH
}

\author{
Ivando Severino Diniz, Maurício de Carvalho Júnior \\ ICTS: Instituto de Ciências e Tecnologia de Sorocaba \\ UNESP - Universidade Estadual Paulista "Júlio de Mesquita Filho" \\ Avenida Três de Março, 511 Alto da Boa Vista, Sorocaba, SP,18.087-180 \\ E-mail: ivando@sorocaba.unesp.br; mau_meca@yahoo.com.br
}

\begin{abstract}
This system was developed to record and send the wireless data to the road police at a distance of up to 100 meters, without needing for the vehicle. The velhice have the velocity register through the tachograph, however to check the speeds, the police need to stop the vehicle and access the registry. The speed data remained in the vehicles for 07 days and after this period will be replaced by new values. If the driver drives the vehicle at high speed, and if not seen by the police, you may be in a stationary vehicle for 7 days. The police can program to receive the data automatically, in case of high speed. The system is composed of two modules: the first module is in the vehicle and is responsible for the acquisition, processing, storage and transmission of traffic information, this data will be transmitted to the second module, which has the function of capturing and displaying the information whenever that the user of the receiver requests the reading and the vehicle is at a distance that allows communication. The system was developed and worked satisfactorily. The system was developed and worked satisfactorily. Currently being deployed to mobile.
\end{abstract}

KEYWORLDS: Tachograph, Digital, Wireless, Automotive.

\section{RESUMO}

Este sistema foi desenvolvido para registrar e enviar os dados sem fios para os policias rodoviário a uma distância de até 100 metros, sem precisar para o veículo. Os veículos possuem o registro das velocidades através do tacógrafo, todavia para verificação das velocidades, os policiais precisam parar o veículo e acessar o registro. Neste sistema, os dados de velocidades permaneceram nos veículos por 07 dias e após este período serão substituídos por novos valores. Caso o condutor conduza o veículo em alta velocidade, e caso não sido visto pela polícia, poderá ficar com veículo parado por 7 dias. A polícia poderá programar para receber automaticamente os dados, para caso de alta velocidade. O sistema é composto de dois módulos: o primeiro módulo se encontra no veículo e é responsável pela aquisição, processamento, armazenamento e transmissão das informações de trafego, esses dados serão transmitidos ao segundo módulo, que tem a função de captar e exibir as informações sempre que o usuário do receptor requisitar a leitura e o veículo estiver a uma distância que possibilite a comunicação. $\mathrm{O}$ sistema foi desenvolvido e funcionou satisfatoriamente. Atualmente está sendo implementado para celular.

PALAVRAS CHAVES: Tacógrafo, digital, wireless, automotivo. 


\section{INTRODUÇÃO}

Há muito tempo o acidente de trânsito vem causando prejuízos enormes à sociedade, milhares de mortes são registradas todos os anos, danos físicos irreparáveis e consequentemente, elevados danos econômicos à toda população.

Investimentos em infraestrutura e conscientização de condutores de veículos e pedestres podem reduzir a níveis muito menores as estatísticas de acidentes de trânsito. Um dos métodos mais difundidos e eficazes de redução de acidentes é a fiscalização, seja através de radares, instalação de tacógrafos ou mesmo o monitoramento feito pela polícia rodoviária.

Assim, em sintonia com essa preocupação crescente na busca de soluções para esse problema crônico e alinhado com as inovações tecnológicas disponíveis foi proposto esse trabalho de graduação que pode contribuir para minimizar o número de acidentes uma vez que a fiscalização será facilitada, o sistema de monitoramento embarcado com tecnologia wireless constitui uma alternativa viável para esse propósito.

O sistema utilizado tem várias vantagens sob o ponto de vista tecnológico, como a utilização de um sistema microcontrolado muito versátil, de alta capacidade de processamento e com baixo consumo de energia, o que é um ponto chave do projeto.

\subsection{Acidentes de trânsito}

Ano após ano os esforços no sentido de aperfeiçoar e de desenvolver novas tecnologias de segurança veicular vêem aumentando. Esse fenômeno tem uma motivação bastante clara, o acidente de transito constitui um grave problema mundial, é a principal causa de morte para homens entre 15 e 44 anos de idade e a quinta causa para mulheres da mesma faixa etária. Segundo estimativas da Organização Mundial de Saúde, em 1998, 1,17 milhão de pessoas morreram em acidentes de trânsito no mundo e mais de 10 milhões de pessoas sofreram algum tipo de ferimento nesses acidentes. A tabela 1 mostra a taxas de morte.

Tabela 1. Taxas de mortes por 10 mil veículos.

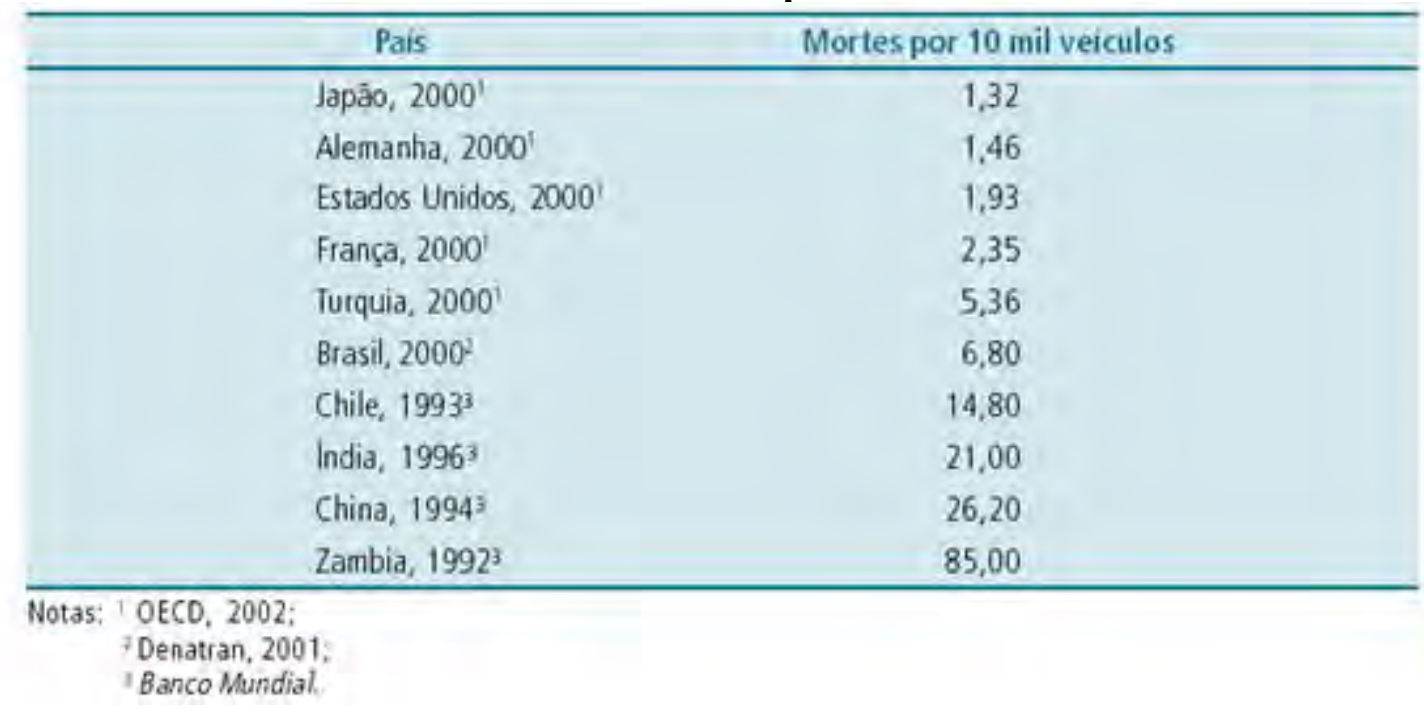

Os acidentes de trânsito causam prejuízos financeiros consideráveis, um estudo realizado no EUA estimou em US\$ 150,5 bilhões os custos dos acidentes de trânsito no ano de 1994, esse valor equivale a 2,2\% do Produto Nacional americano. 


\subsection{Acidentes de trânsito no Brasil}

No Brasil, o acidente de trânsito é o segundo maior responsável por mortes causadas por fatores externos, à tabela 2 o mostra a estimativa para o ano de 2002.

Tabela 2. Número de mortes por causas externas em 2002. Mortes por causas externas em $2002 \quad \%$

\begin{tabular}{lrr} 
1. Homicídios & 49.816 & 39,4 \\
2. Acid. transporte & 33.288 & 26,3 \\
3. Demais causas externas & 23.163 & 18,3 \\
4. Intenç.indeterm & 12.557 & 9,9 \\
5. Suicídios & 7.726 & 6,1 \\
\hline Total por causas externas & 126.550 & 100,0
\end{tabular}

Fonte: Ministério da Saúde/SVS - Sistema de Informações sobre Mortalidade - SIM

A experiência brasileira de levantamento de dados de acidentes repete o que ocorre na maioria dos países em desenvolvimento e também em alguns países mais industrializados: existe uma grande diferença entre o número real de acidentes de trânsito ocorridos e o número registrado pelos órgãos de trânsito, principalmente no caso de acidentes sem vítimas ou com pequenos danos materiais.

As estatísticas oficiais do Departamento Nacional de Trânsito do Ministério das Cidades - Denatran, que consideram as mortes ocorridas no local do acidente, registram mais de 20 mil mortos por ano e centenas de milhares de feridos; as do Ministério da Saúde, que incorporam dados do sistema de saúde, indicam a ocorrência de cerca de 30 mil mortos em decorrência dos acidentes de trânsito, conforme tabela3.

Tabela 3. Total de acidentes de trânsito entre 1961 e 2000.

\begin{tabular}{rrrcc}
\hline Ano & Feridos & Mortos & Mortos/100 mil pessoas & Mortos/10 mil veiculos \\
\hline 1961 & 23.358 & 3.356 & 4,6 & 53,6 \\
1971 & 124.283 & 10.692 & 11,1 & 34,4 \\
1981 & 243.001 & 19.782 & 15,9 & 17,0 \\
1991 & 248.885 & 23.332 & 15,1 & 11,3 \\
2000 & 358.762 & 20.049 & 11,8 & 6,8 \\
\hline
\end{tabular}

Fonte: Denatran.

Segundo dados da OMS (Organização Mundial da Saúde), o país é o quarto colocado em número de mortes nas Américas. O Brasil registra mais de 47 mil mortes no trânsito por ano e 400 mil pessoas ficam com algum tipo de sequela. O custo dessa epidemia ao país é de R\$ 56 bilhões, segundo levantamento do Observatório Nacional de Segurança Viária.

\section{DESCRIÇÃO TEÓRICA}

\subsection{O microcontrolador ARM}

Os processadores ARM de 32 bits surgiram buscando atender duas fortes tendências do mercado, a busca por produtos com baixo consumo de energia e com alta capacidade de processamento. 
A sigla ARM significa Advanced RISC Machine onde RISC significa Reduced Instruction Set Computer, ou seja, essa arquitetura contém um conjunto simples e reduzido de instruções visando a otimização de desempenho.

\subsection{O LPC2148}

O LPC2148 da Philips é baseado no núcleo ARM7TDMI-S com suporte à emulação (usando a porta J-TAG) aliada a uma memória de programa Flash de alta velocidade e uma interface de alta velocidade permite a execução a $60 \mathrm{MHz}[1]$. Para aplicações em que o tamanho do programa é importante, podemos contar também com o modo Thumb, com o qual podemos enxugar 30\% do espaço da memória de programa. A seguir, é apresentado o diagrama de blocos do LPC2148 na figura 01.

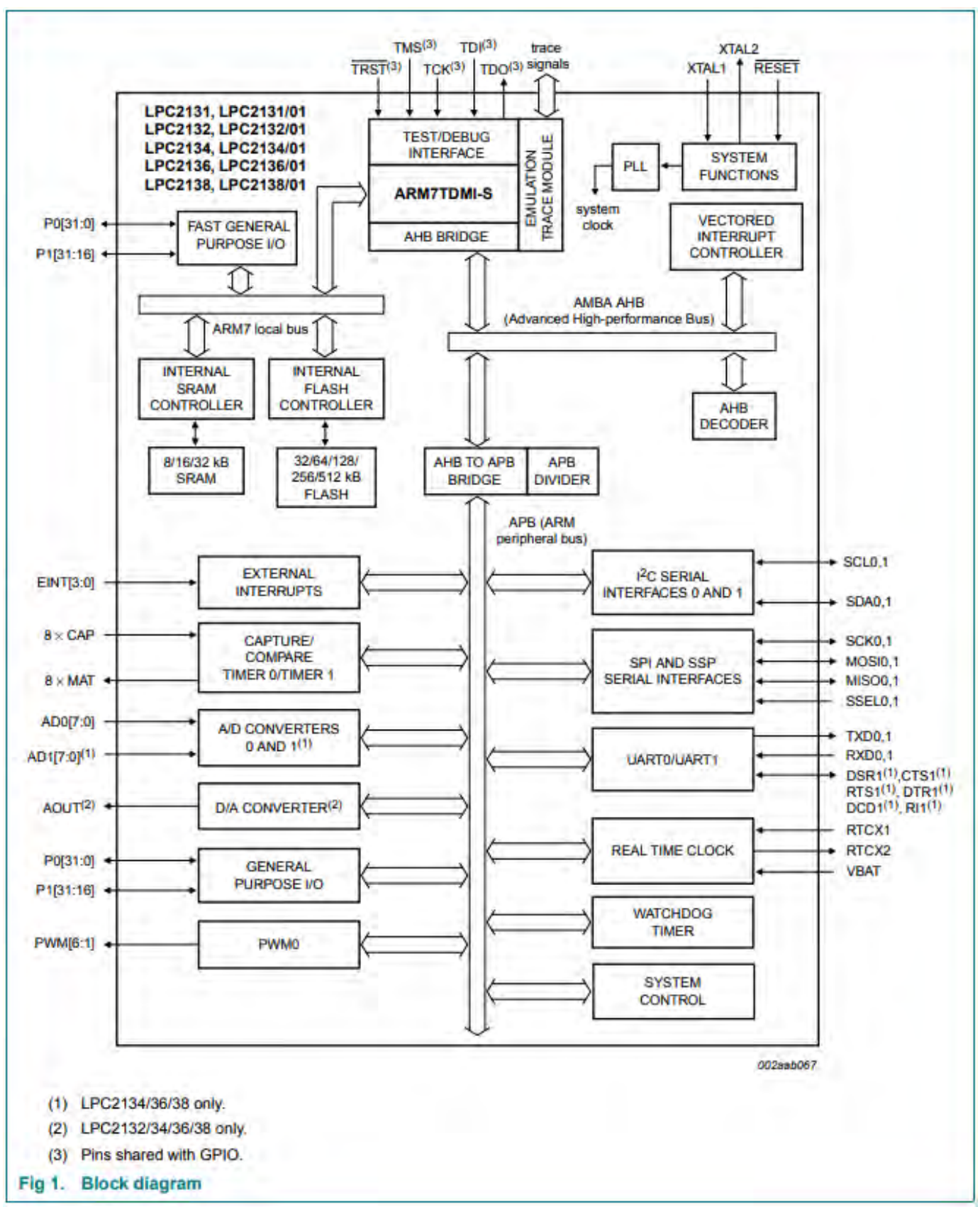

Figura 1. Diagrama de blocos do LPC2148. 


\subsection{Redes de comunicação sem fio}

As redes de comunicação sem fio já são uma realidade presente no dia a dia de usuários de computadores, celulares, PDA's, GPS's, entre outros. Porem, ainda há muito a ser explorado em termos de novas tecnologias de comunicação sem fio e conseqüentemente novas aplicações.

As recomendações do IEEE (Institute of Electrical and Eletronics Engineers), particularmente as recomendações da série IEEE 802.11, são os exemplos mais conhecidos para os padrões de redes sem fio e que nos permitem considerar a existência de quatro grandes grupos:

- WPAN (Wireless Personal Area Network) - Onde estão as tecnologias wireless de pequeno alcance (entre 10 e 100 metros). É um padrão para redes locais, definido pelo IEEE 802.15, para o endereçamento de redes sem fio que utilizam dispositivos portáteis ou móveis tais como PC's, PDA's, periféricos, celulares, pager's, etc;

- WLAN (Wireless Local Area Network) - Onde estão as tecnologias sem fio destinadas à interligação de redes locais com alcance entre 100 e 1600 metros. Trata-se de padrão implementado como extensão ou alternativa para as redes com cabeamento convencional (par metálico ou fibra óptica);

- WMAN (Wireless Metropolitan Area Network) - Neste grupo temos as tecnologias que tratam dos acessos de banda larga para última milha para redes em áreas metropolitanas, com alcance em torno de $6 \mathrm{~km}$;

- WWAN (Wireless Wide Area Network) - Neste grupo estão as tecnologias voltadas para redes de longa distância em telecomunicações, atendendo aos serviços de voz e alguns serviços de dados.

\subsection{Protocolo ZigBee}

Atualmente o foco das redes wireless comerciais se encontra no contexto das redes locais (WLAN's), tanto em soluções proprietárias como nos padrões desenvolvidos pelo IEEE, por exemplo. Com a evolução natural das tecnologias das redes sem fio, estas passaram a atender não só as aplicações corporativas mais sofisticadas como também aquelas envolvendo pequenos volumes de dados que exigem baixas taxas de transmissão como, por exemplo, o controle de equipamentos eletroeletrônicos[5]. A figura 02 mostra a evolução.

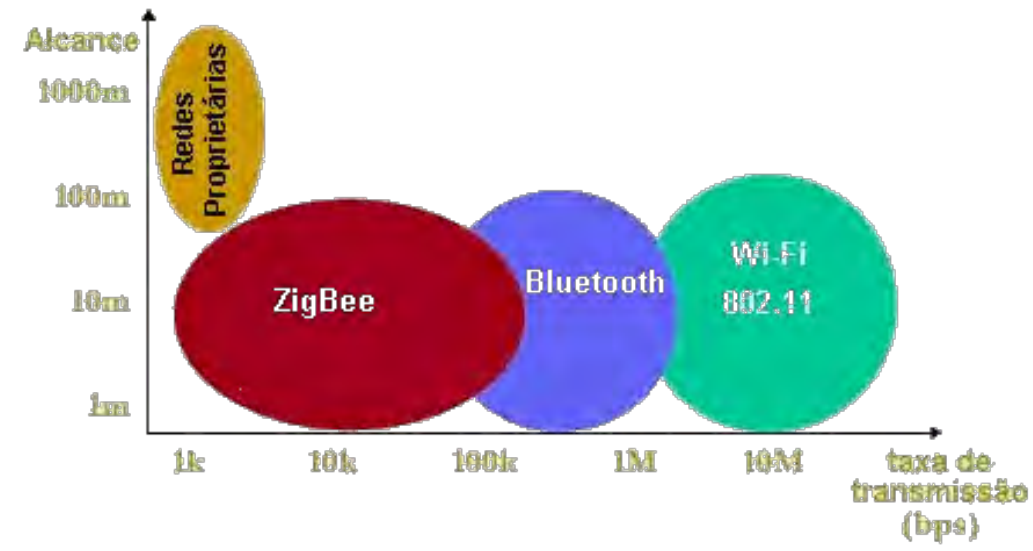

Figura 2. Comparativo entre as redes de comunicação sem fio.

O padrão ZigBee foi desenvolvido para se tornar uma alternativa de comunicação em redes que não necessitem de soluções mais complexas para seu controle, barateando assim os 
custos com a aquisição, instalação de equipamentos, manutenção e mão de obra. Trata-se de uma tecnologia relativamente simples, que utiliza um protocolo de pacotes de dados com características específicas, sendo projetado para oferecer flexibilidade quanto aos tipos de dispositivos que pode controlar.

\subsection{Sensor de Velocidade Veicular (VSS)}

O sensor de velocidade do veículo (VSS - Vehicle Speed Sensor) fornece um sinal com forma de onda cuja freqüência é proporcional à velocidade do veículo, figura 3 .

Normalmente o sensor é montado no câmbio do veículo. Se o veículo se movimenta a uma velocidade relativamente baixa, o sensor produz um sinal de baixa frequência. À medida que a velocidade aumenta, o sensor gera um sinal de freqüência maior. O módulo de injeção utiliza a freqüência do sinal gerado do sensor de velocidade para: identificar o veículo parado ou em movimento, enriquecimento do combustível durante a aceleração, corte do combustível (cut-off), controle da rotação em marcha lenta, permite em alguns tipos de injeção que o ventilador do radiador seja desligado em velocidades elevadas, acionar a embreagem do conversor de torque em veículos equipados com transmissão automática. Ainda atua na luz indicativa de mudança de marchas nos veículos equipados com esse dispositivo e transmissão manual e computador de bordo para cálculos de distância, consumo e etc. O sensor de velocidade pode ser encontrado nas seguintes configurações: sensor magnético ou de relutância variável e sensor de efeito hall.

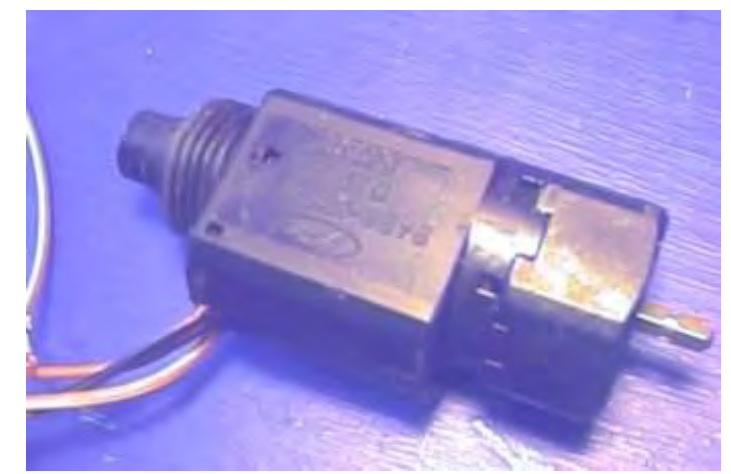

Figura 3 . Sensor de Velocidade Veicular (VSS).

\subsection{Sensor magnético ou de relutância variável}

O sensor de relutância variável tem ampla aplicação na eletrônica automotiva. Nos sistemas de freios ABS, por exemplo, é utilizado como sensor de velocidade das rodas. $\mathrm{Na}$ injeção eletrônica pode vir a exercer as funções de sensor de rotação, velocidade do veículo, posição da árvore de manivelas (ou ponto morto superior) e sensor de fase do comando de válvulas.

É constituído basicamente por: Roda dentada (ou fônica), imã permanente, núcleo ferromagnético, bobina, fios da bobina, malha de blindagem e conector do sensor. A roda fônica pode estar montada na árvore de manivelas (dentro ou fora do bloco do motor), comando de válvulas ou eixo distribuidor. Seu número de dentes varia de acordo com sua função e aplicação; veja alguns exemplos: 
O sensor de relutância, ao contrário do sensor HALL, não necessita de alimentação (positiva e negativa) para emitir sinal à unidade de comando eletrônico-UCE. Seu sinal é gerado por indução eletromagnética. O movimento da roda fônica faz variar a intensidade do campo magnético do imã permanente sobre a bobina do sensor. Essa variação provoca o surgimento de uma tensão de corrente alternada (VAC) induzida no enrolamento da bobina (sinal do sensor). $\mathrm{O}$ sinal do sensor varia principalmente em função de sua distância à roda fônica, da rotação do motor (quanto maior a rotação maior a tensão VAC enviada) e do número de dentes que a roda fônica possui.

O cabo do sensor é completamente envolvido por uma malha metálica denominada malha de blindagem. Essa malha é aterrada na massa do veículo e objetiva evitar que interferências eletromagnéticas sejam confundidas com o sinal do sensor. Nos veículos Injetados na falta do sinal dos sensores de rotação, posição da árvore de manivelas ou ponto morto superior o sistema não entra em funcionamento. Nos sistemas de freios ABS, quando o sensor de velocidade de uma ou mais rodas deixa de atuar, o controle eletrônico da frenagem fica comprometido.

\subsection{Sensor de efeito Hall}

O Sensor de Efeito Hall trabalha de forma muito parecida ao sensor de relutância variável, mas ao contrário do indutor, o Sensor de Efeito Hall é muito pequeno e é ativado pôr um campo magnético. O resultado e um sensor menor e mais leve, que gera um sinal mais claro.

O sensor Hall fica localizado na carroceria próximo da roda, ele consiste de uma pequena chapa de material semicondutor através da qual passa uma corrente I, montada em frente a um imã que produz um campo magnético aproximadamente uniforme de magnitude $\mathrm{B}$. Como resultado, é gerado um sinal de tensão transversal de magnitude VH (tensão Hall). Quando outro dispositivo (outra chapa metálica de elevada permeabilidade magnética), presa na roda, passa entre o imã e a chapinha semicondutora, anulando o campo, a tensão de saída do sensor, $\mathrm{VH}$, cai a zero. Isso produz como sinal de saída um pulso de forma aproximadamente quadrada, que pode ser utilizada pelo computador de bordo para medir a velocidade angular da roda.

\section{Materiais e Métodos}

A escolha dos componentes que farão parte do sistema levou em conta a existência de sistemas capazes de atender aos requisitos desse projeto, conhecimento existente na concepção de sistemas microcontrolados e a possibilidade de utilizar sistemas com tecnologia de ponta.

\subsection{Desenvolvimento do Hardware}

\subsubsection{Módulo eLPC64 (sistema microprocessado)}

Para facilitar a implementação do projeto optou-se pelo uso do Módulo eLPC64 da eSysTech, representado na figura4, pois nesse SOM (System On Module) já estão implementadas as funcionalidades essenciais e as funcionalidades especificas do projeto podem ser implementadas através de uma interface padrão. 

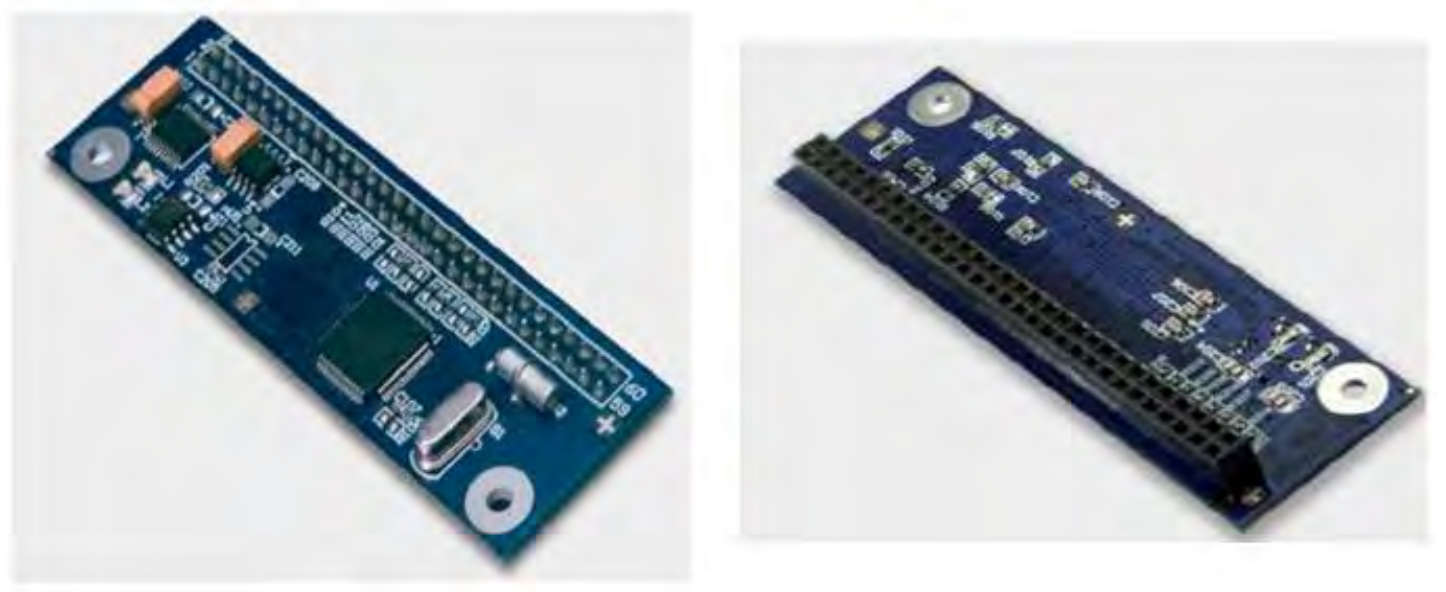

Figura 4. Aspectos físicos do módulo eLPC64 da eSysTech.

O esquema elétrico da bandeira eLPC64 fornecido pela eSysTech é apresentado nas Figuras 18 e 19. Características Técnicas

Algumas das principais características do Módulo eLPC64 são listadas abaixo:

- Possui um header de 60 pinos para conexão com a placa base

- Suporte aos processadores NXP LPC21XX com encapsulamento NQFP64

- Alimentação externa de $5 \mathrm{~V} \pm 1 \mathrm{~V}$. Reguladores de tensão incluídos no módulo

- Regulador de tensão LDO para processador e dispositivos externos com capacidade de fornecimento de até $300 \mathrm{~mA}$

- Cristais para o processador $(20 \mathrm{MHz})$ e para o RTC $(32,768 \mathrm{MHz})$

\subsubsection{Módulo XBee}

O módulo de comunicação ZigBee adquirido foi o XBee Serie 2 desenvolvido pela empresa MaxStream[6], representado na figuira 5.

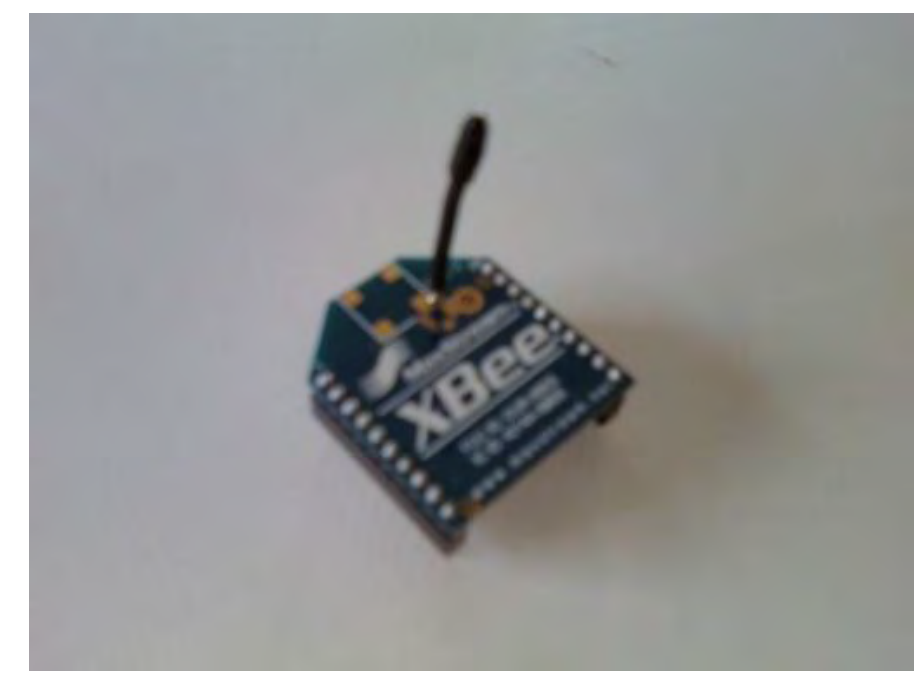

Figura 5. Aspecto físico do módulo XBee da MaxStream.

A tabela 4 apresenta a pinagem do módulo XBee utilizado no projeto com uma breve descrição das funcionalidades de cada pino. 
Tabela 4. Pinagem do módulo XBee serie 2 da MaxStream.

\begin{tabular}{|c|c|c|c|}
\hline Pino & Nome & Direção & Descrição \\
\hline 1 & VCC & - & Alimentação 3,3V \\
\hline 2 & DOUT & Saída & Saída de dados da UART \\
\hline 3 & DIN/CONFIG & Entrada & Entrada de dados da UART \\
\hline 4 & DIO12 & Ambas & I/O Digital 12 \\
\hline 5 & RESET & Entrada & Reseta o módulo \\
\hline 6 & PWM0/RSSI/DIO10 & Ambas & $\begin{array}{c}\text { Saída do PWM 0 / Indicador de força } \\
\text { do sinal de RF / I/O Digital 10 }\end{array}$ \\
\hline 7 & PWM1/DIO11 & Ambas & I/O Digital 11 \\
\hline 8 & {$[$ Reservado] } & - & Não conectar \\
\hline 9 & DTR/SLEEP_RQ/DI & Omb & Entrada digital 8 \\
\hline 10 & GND & - & Terra \\
\hline 11 & DIO4 & Ambas & I/O Digital 4 \\
\hline 12 & CTS/DIO7 & Ambas & Controle de fluxo CTS / I/O Digital 7 \\
\hline 13 & ON/SLEEP/DIO9 & Saída & $\begin{array}{c}\text { Indicador de estado do módulo / I/O } \\
\text { Digital 9 }\end{array}$ \\
\hline 14 & [Reservado] & - & Não conectar \\
\hline 15 & Associação/DIO5 & Saída & Indicador de associação / I/O Digital 5 \\
\hline 16 & RTS/DIO6 & Saída & Controle de fluxo RTS / I/O Digital 6 \\
\hline 17 & AD3/DIO3 & Saída & Entrada analógica 3 / I/O Digital 3 \\
\hline 18 & AD2/DIO2 & Saída & Entrada analógica 2 / I/O Digital 2 \\
\hline 19 & AD1/DIO1 & Saída & Entrada analógica 1 / I/O Digital 1 \\
\hline 20 & $\begin{array}{c}\text { AD0/DIO0/botão de } \\
\text { comissionamento }\end{array}$ & Saída & Entrada analógica 0 / I/O Digital 0 \\
\hline
\end{tabular}

Esse módulo é ideal para aplicações de baixo custo e baixo consumo de energia, alem disso, são fáceis de utilizar visto que nenhuma configuração é necessária em redes simples. As principais características desse módulo são:

- Taxa de transmissão de $250 \mathrm{kbps}$

- Banda de freqüência de $2,4 \mathrm{GHz}$

- Alcance indoor de $30 \mathrm{~m}$

- Alcance outdoor de $90 \mathrm{~m}$

- Interface serial 3,3CMOS serial UART

- Alimentação 2,8-3,4Vdc

\subsubsection{Módulo embarcado no veículo}

O sistema que será instalado no veículo não terá interface gráfica (sistema fechado) apenas conterá um botão e um LED para testes ou mesmo para indicar que esta sendo realizada a transmissão dos dados.

A figura 6 abaixo são exibidas as imagens da placa após montagem final. 

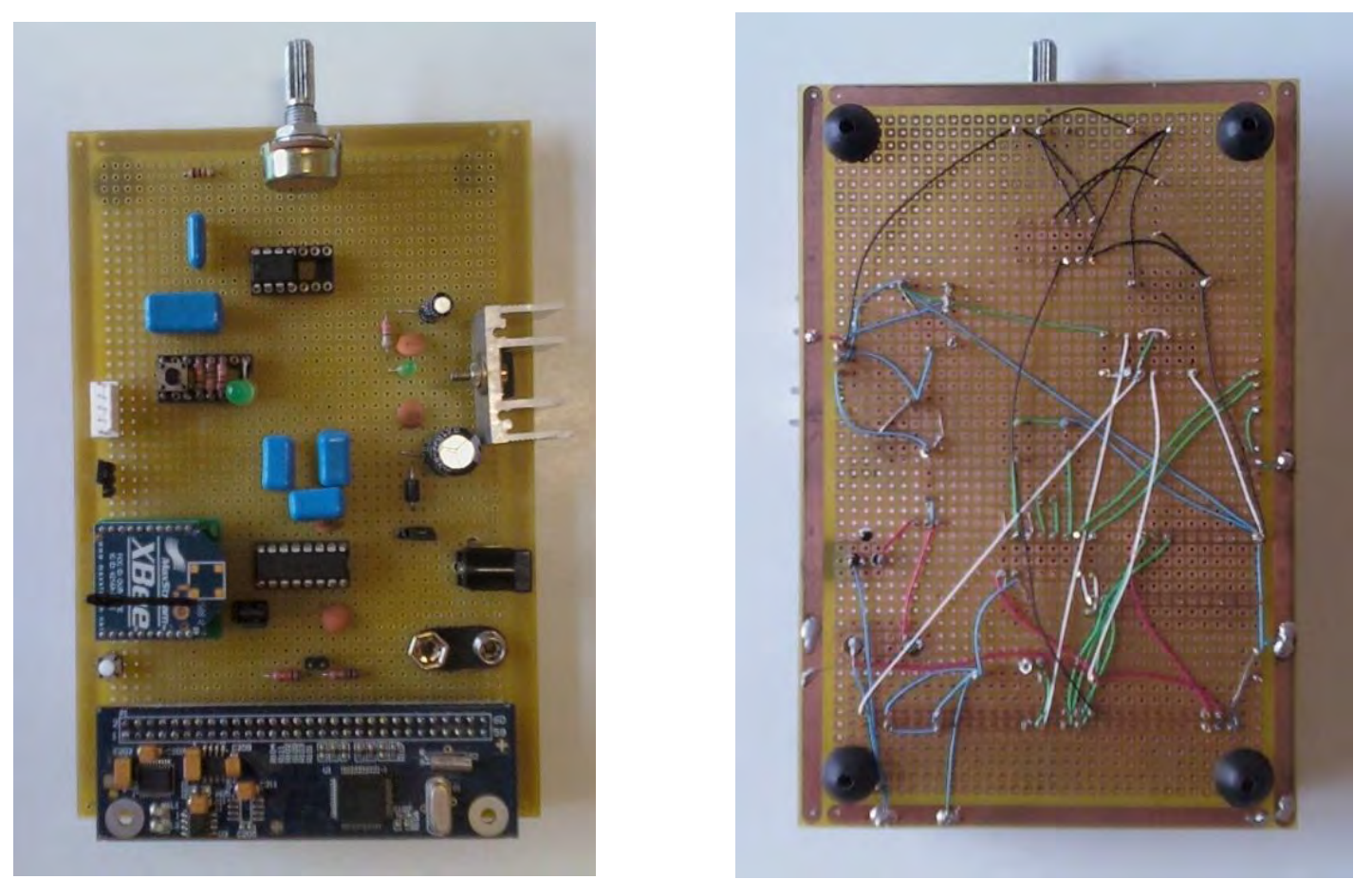

Figura 6. Aspecto físico da placa de aquisição e transmissão de dados embarcada no veículo - frente e verso.

A seguir, as figuras 7 e 8, são apresentados os esquemas elétricos das diversas partes que compõem o sistema de aquisição embarcado no veículo.

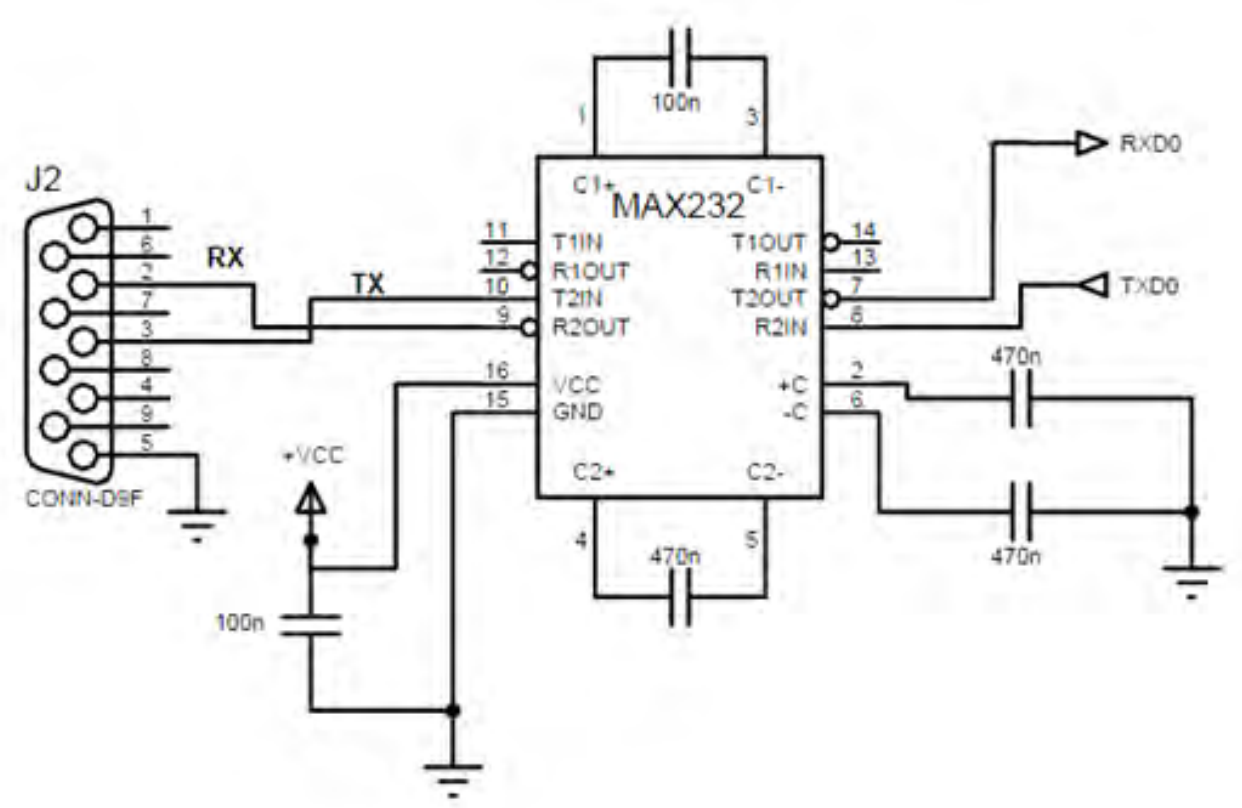

Figura 7. Ligação RS232 com o PC. 

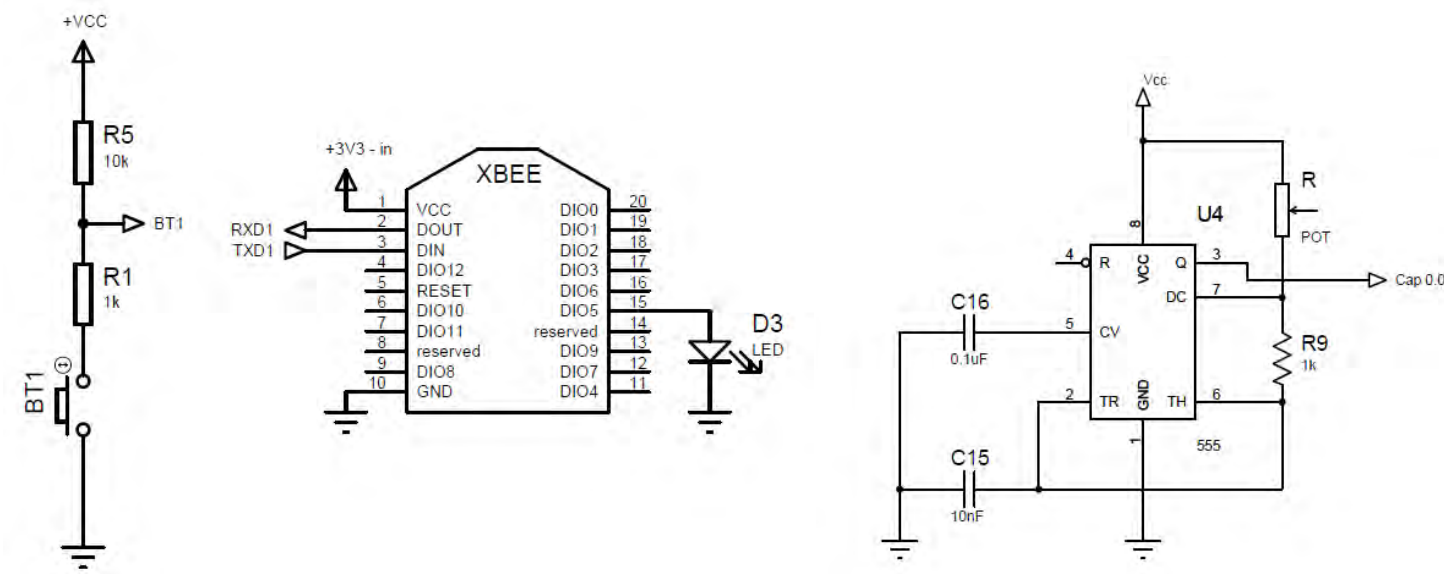

Figura 8. Esquema elétrico do botão e do módulo XBee e multivibrador monoastável com 555.

\subsubsection{Módulo portátil de leitura}

O circuito terá como interface gráfica um display LCD (2x16), alem disso, serão utilizados três botões.

- Botão 1 (Menu): Responsável por selecionar quais dados serão exibidos

- Botão 2: Exibe data/ hora ou faz leitura da velocidade instantânea.

- Botão 3: Incrementa data/hora ou exibe máximas velocidades

- Botão 4: Decrementa data/hora ou exibe tempo de condução continua.

Representados nas figuras: 9, 10 e 11.
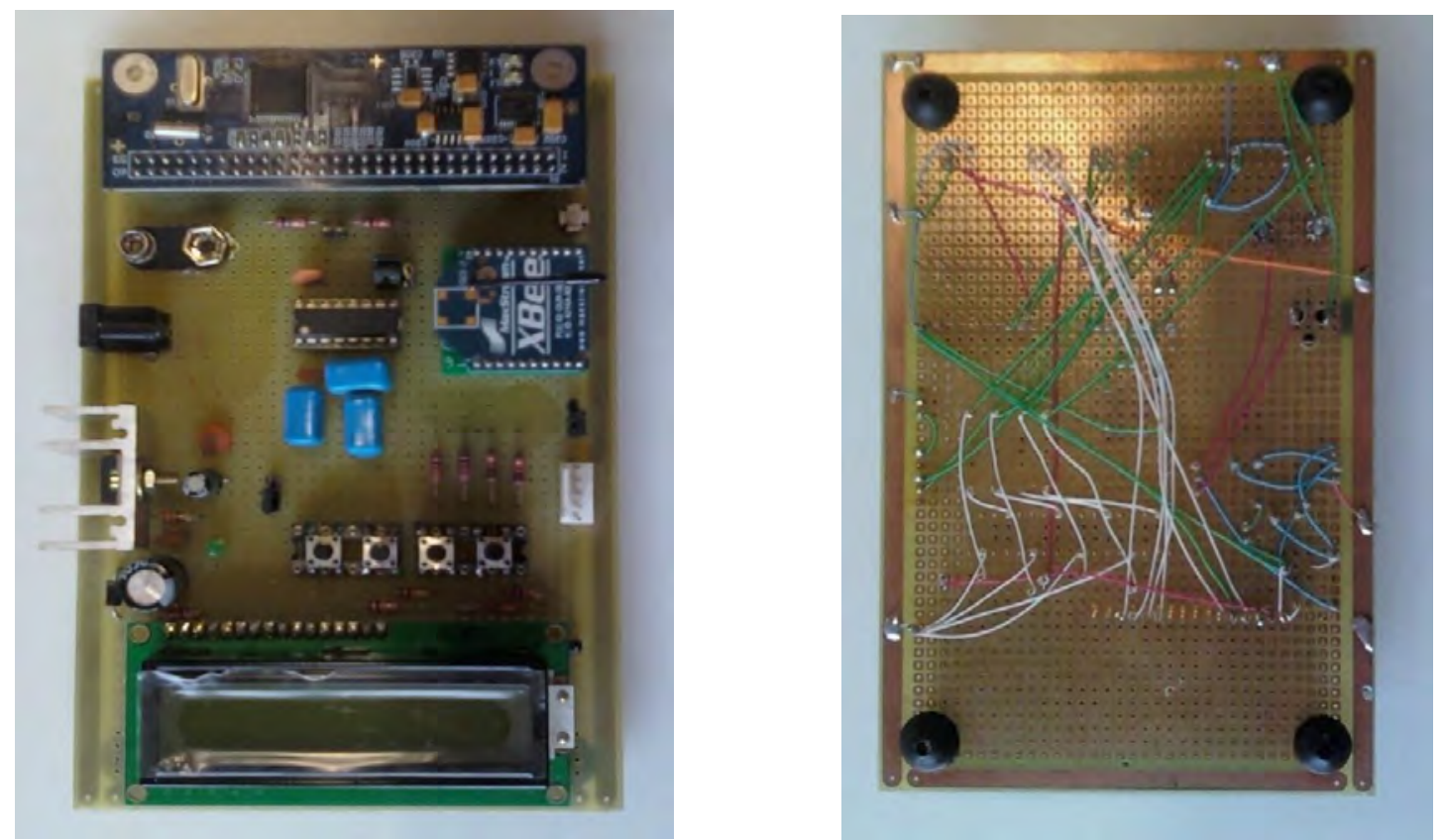

Figura 9. Aspecto físico do módulo portátil de leitura de dados - frente e verso 

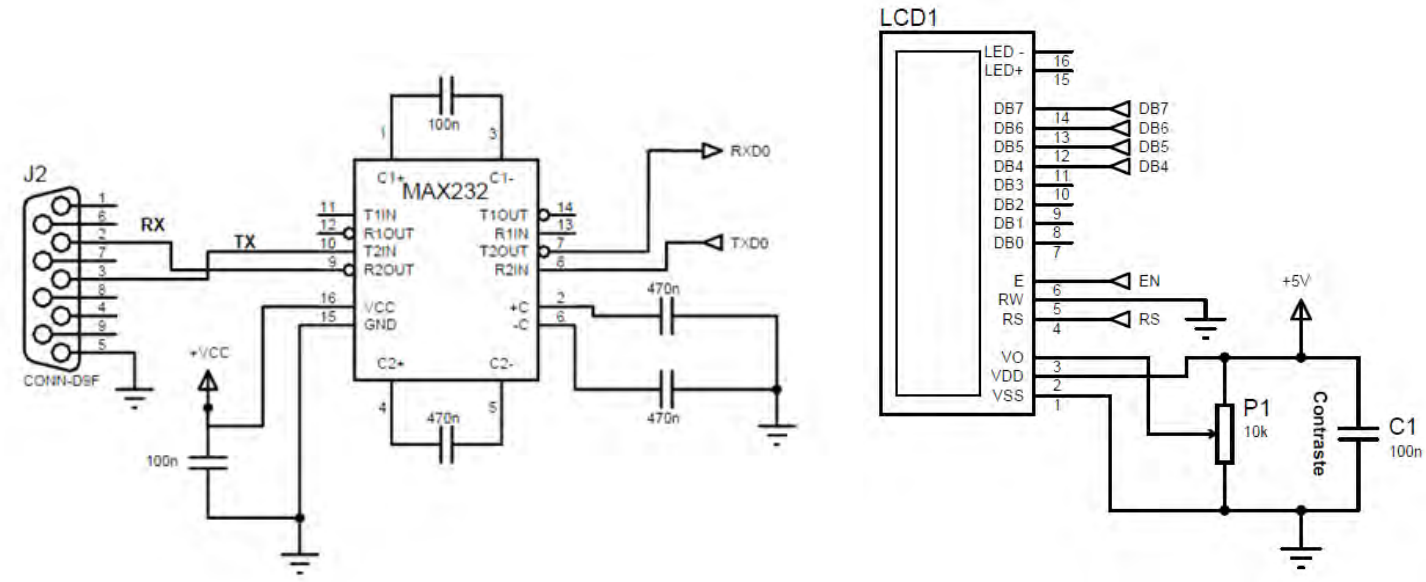

Figura 10. Ligação RS232 com o PC e do display de cristal líquido.
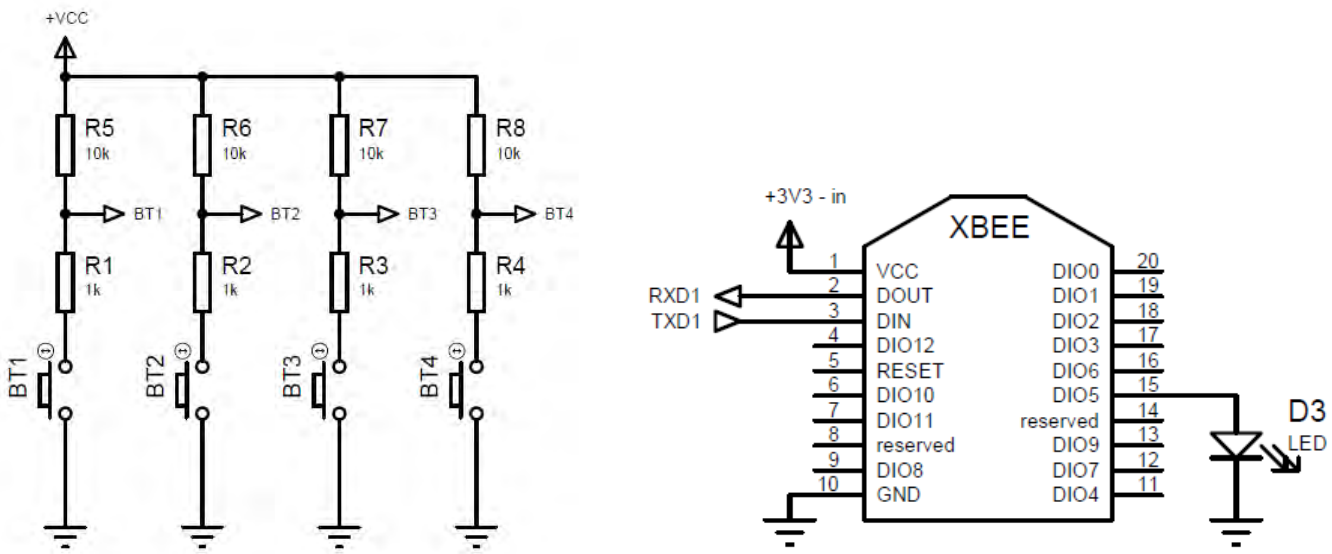

Figura 11. Esquema das ligações dos botões e do módulo XBee.

\subsection{Desenvolvimento do Software}

Após finalizar a montagem do Hardware foram iniciadas as atividades de programação do projeto, para tanto, foram utilizados os softwares $\mu$ Vision 3 (Demo) da Keil para programação do ARM em linguagem C[2], Flash Magic para gravação do programa nas placas e X-CTU para configuração dos módulos de comunicação ZigBee.

\subsection{1 $\mu$ Vision 3 (Demo)}

$\mathrm{O} \mu$ Vision 3 (Demo) produzido pela Keil combina um gerenciador de projetos, editor de códigos fontes, debbuger e um completo ambiente de simulação em um único e poderoso sistema. A plataforma de desenvolvimento $\mu$ Vision (Demo)é facil de usar e possui facilidades para uma rápida criação de programas funcionais. 


\subsection{2 Flash Magic}

Para fazer a transferência do arquivo em linguagem de máquina (extensão HEX) para o ARM, foi utilizado o Flash Magic. A tela principal do programa é mostrada figura 12.

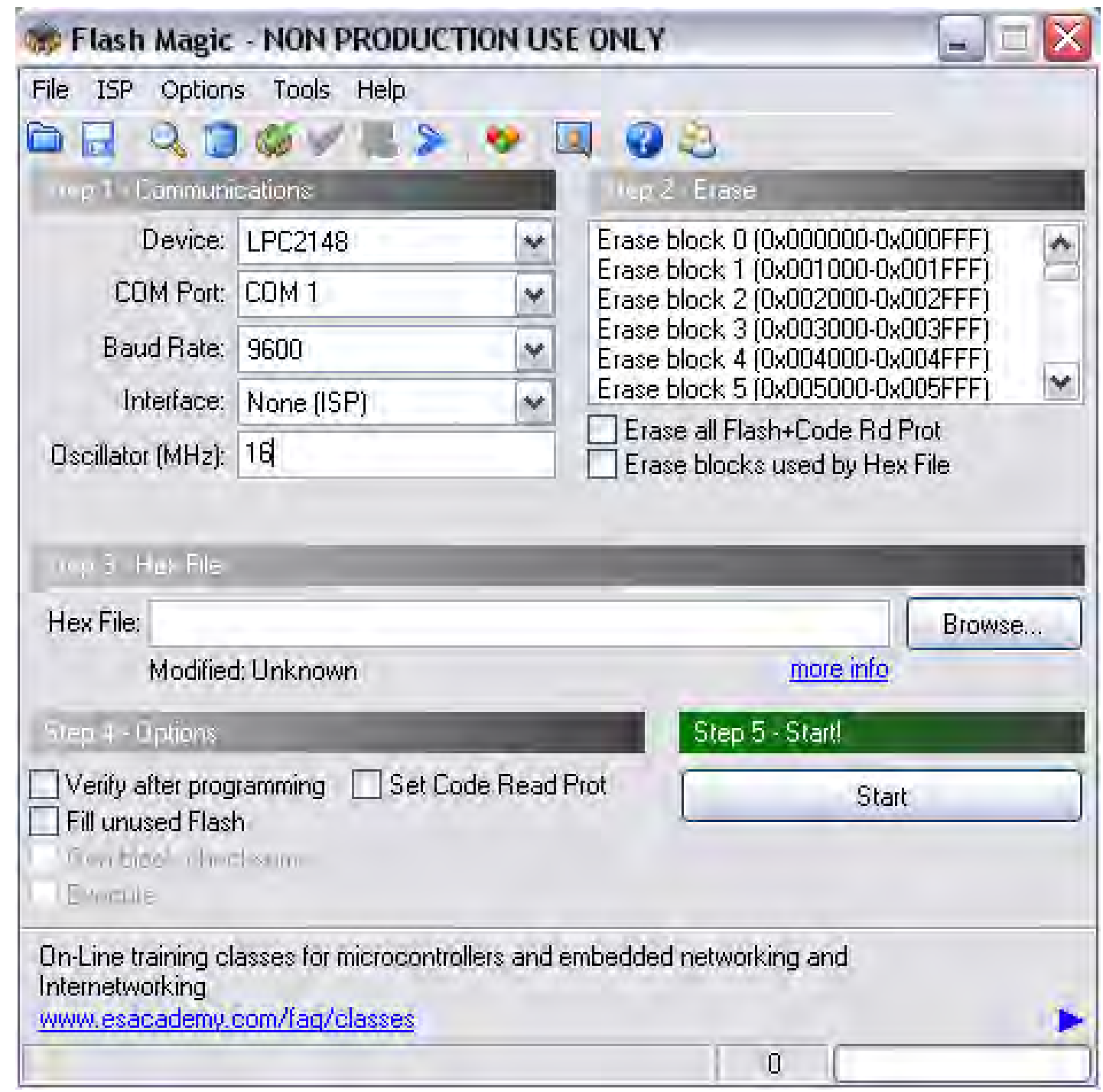

Figura 12. Tela do Flash Magic.

Os passos necessários para realizar a gravação são descritos a seguir.

- Selecionar o dispositivo

- Selecionar a porta serial

- Selecionar a taxa de transmissão (baud rate)

- Selecionar interface para gravação

- Escolher uma freqüência para gravação

- Selecionar para apagar os dados do ARM

- Localizar o arquivo .hex desejado

- Dar um reset no ARM com o jumper no pino BSL

- Clicar em start

- Remover o jumper após gravação

- Dar reset novamente 


\subsection{X-CTU}

O programa X-CTU, disponível no site da Digi International, permite configurar e programar a comunicação com o módulo XBee, conectado a uma porta serial, conforme figura 13.

A aba "PC Settings" permite configurar a comunicação serial selecionando o baud rate, o controle de fluxo, o tamanho do pacote, a paridade, os bits de parada e se o módulo encontrase no modo AT ou API.

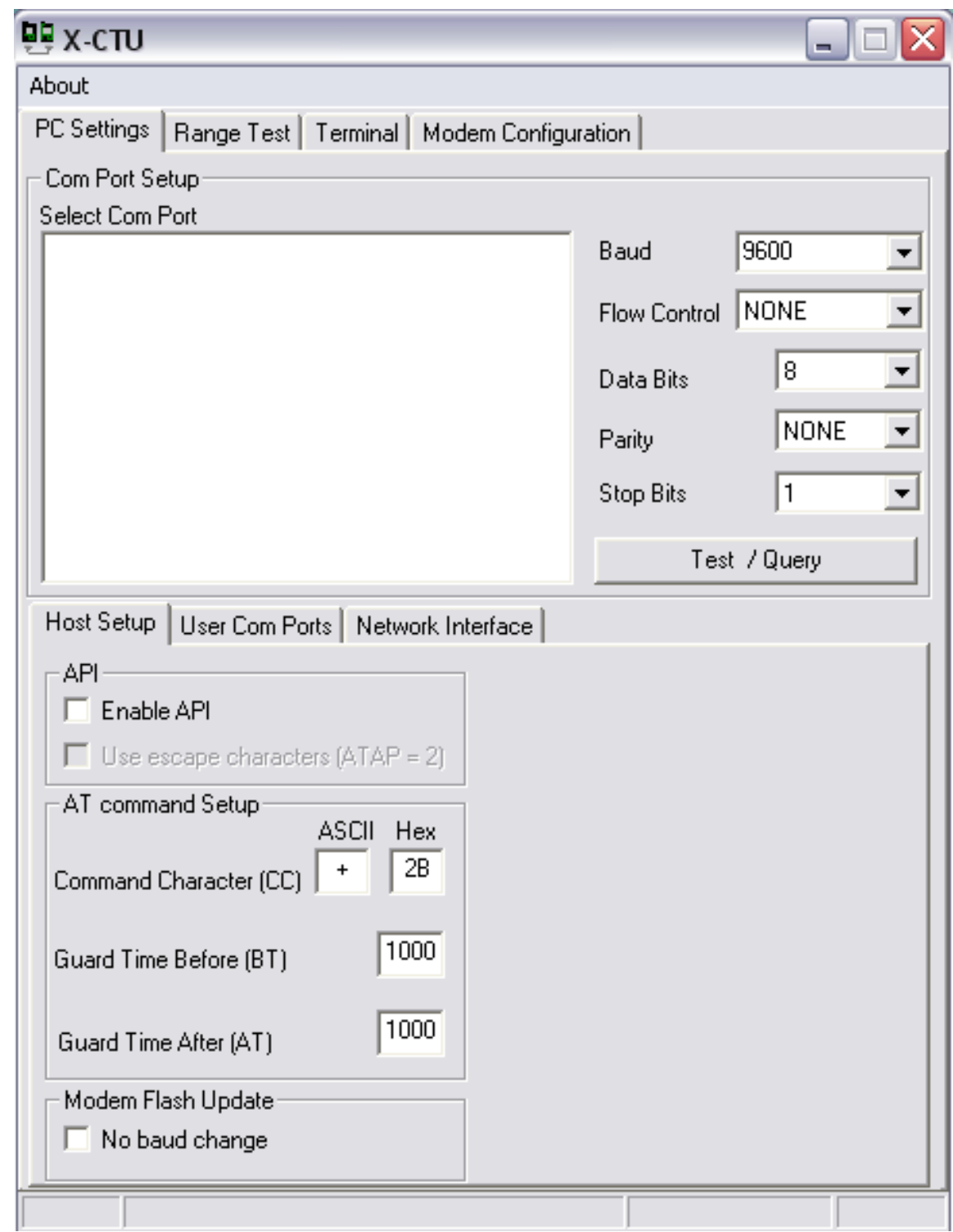

Figura 13. Configuração do software X-CTU 


\section{RESULTADOS}

Para realização dos testes e validação do projeto, foi utilizado um CI LM555 configurado como multivibrador astável, ou seja, um gerador de pulsos variável, assim, com o auxilio de um potenciômetro o valor da freqüência de saída do LM555 produz um sinal semelhante ao de um sensor de velocidade instalado no eixo de um veiculo, sendo os sensores mais comuns são os de Efeito Hall. Para projetar o esquema de ligação do LM55 foi considerada um faixa de variação de freqüência capaz de produzir uma variação de velocidade de 0 à $250 \mathrm{Km} / \mathrm{h}$.

Tomando como base um veículo popular, os valores utilizados para simulação foram de 16 pulsos por volta do eixo, e o valor adotado para o diâmetro do pneu foi de $0,4191 \mathrm{~m}$. Dessa forma sabendo-se o numero de pulsos em um segundo é possível determinar a velocidade linear do veiculo da seguinte forma:

$$
\mathrm{V}=\frac{(2 \times \pi \times \text { raio } \times f)}{16}
$$

Onde f é a freqüência em Hertz, ou seja, o numero de pulsos por segundo capturado pelo microprocessador.

Com o valor da velocidade instantânea, o próximo passo foi calcular as máximas velocidades para períodos pré-definidos, 60 segundos, 60 minutos e 24 horas.

Fixando o valor do potenciômetro ligado a entrada do LM555 é possível verificar a captura e transmissão da velocidade para o modulo de leitura.

Ao ligar o sistema e apertar o Botão 1 são exibidas duas opções ao operador como mostra a figura 14 e 15:

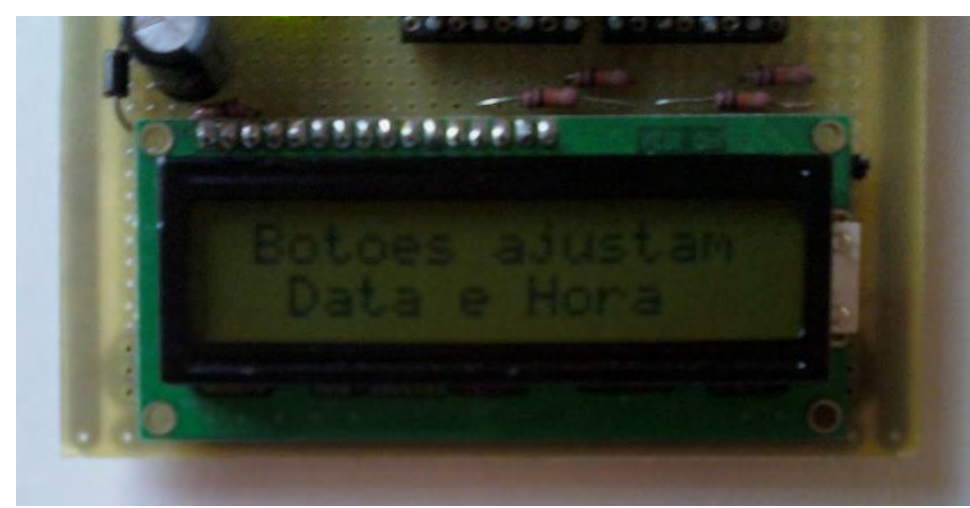

Figura 14. Tela no modo de exibição de data e hora.

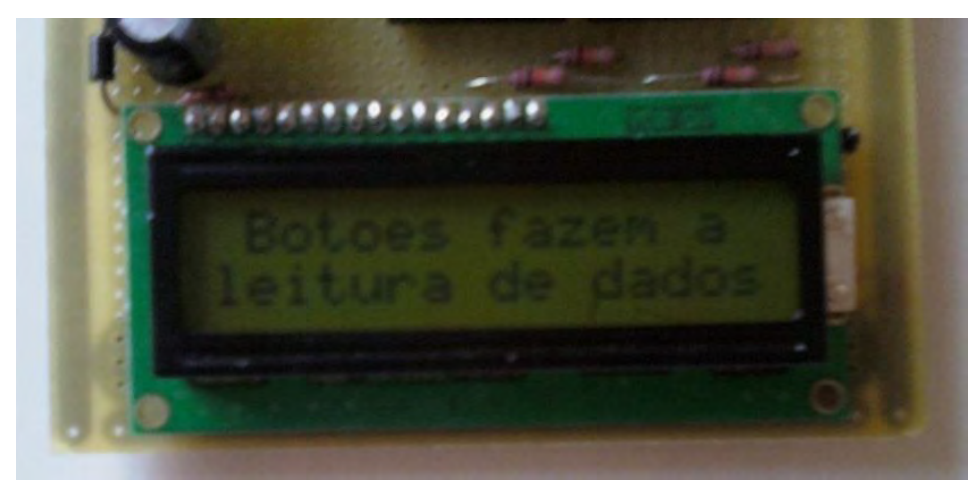

Figura 15. Tela no modo de leitura dos dados. 
Pressionando o botão 2 no modo de exibição de data e hora, a seguinte tela é mostrada no LCD, da figura 16.

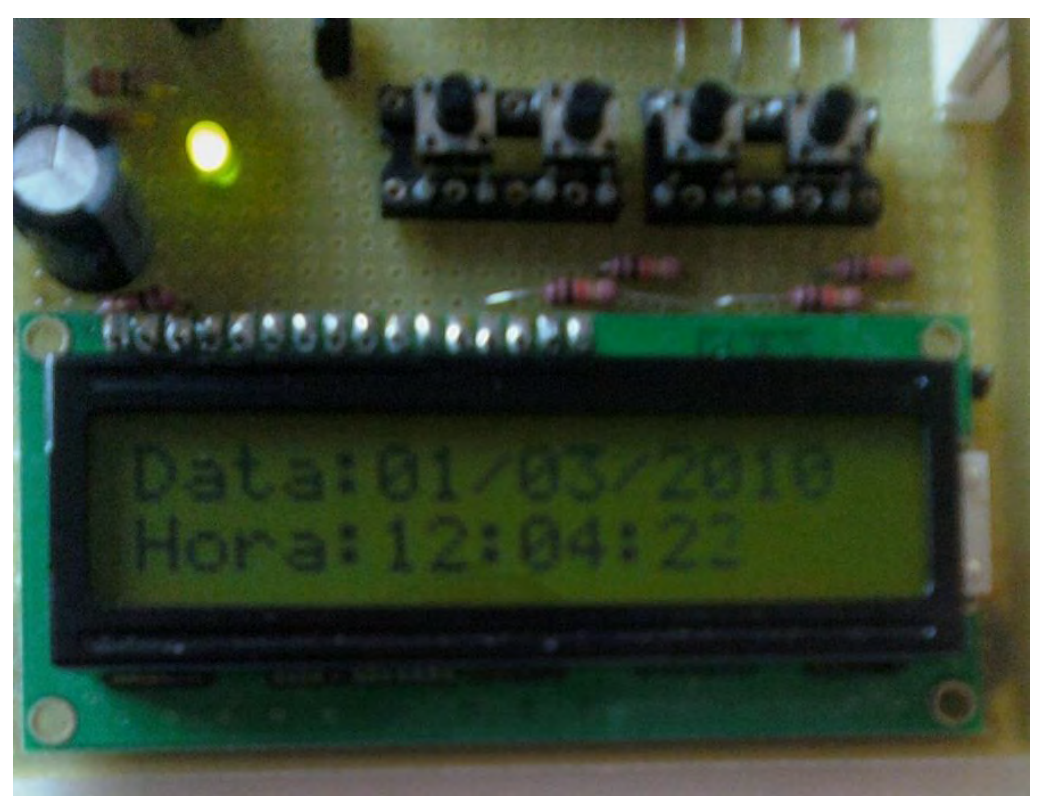

Figura 16. Tela com exibição de data e hora.

Nesse modo também pode-se ajustar a data e hora, o botão 2 alterna entre os campos a serem alterados, o botão 3 incrementa o valor atual e o botão 4 decrementa.

Já no modo de captura de dados da placa embarcada a tela exibida no LCD é a da figura.

Para uma freqüência de $16 \mathrm{~Hz}$ a velocidade produzida será de:

$$
\mathrm{V}=2,63 \mathrm{Km} / \mathrm{h}
$$

No sistema, todos os dados disponíveis no módulo embarcado, são enviados de uma só vez ao modulo de leitura e este faz a seleção de qual deles será exibido. Portanto os dados são enviados na forma de um vetor (dados) com oito posições, onde cada posição corresponde ao seguinte dado:

- Dados[0] - valor da velocidade atual do veículo

- Dados[1] - valor da máxima velocidade no último minuto

- Dados[2] - valor da máxima velocidade na última hora

- Dados[3] - valor da máxima velocidade no último dia

- Dados[4] - valor do segundo do tempo de condução

- Dados[5] - valor do minuto do tempo de condução

- Dados[6] - valor da hora do tempo de condução

- Dados[7] - bit de parada ('>’)

\subsection{Verificando a eficácia dos cálculos do modulo embarcado}

Para buscar encontrar possíveis problemas na programação foi bastante utilizada a depuração do uVision3 (demo). Analisando os trechos mais importantes do código pode-se verificar se o sistema esta se comportando como esperado. No trecho a seguir foi verificado que a interrupção do RTC, configurada para ser executada a cada segundo, foi corretamente chamada, fivura 17.

Dentro dessa interrupção temos o código responsável por capturar o valor armazenado no registrador de captura do Timer 0 do LPC2148, assim, a cada borda de subida detectada pelo 
pino de captura (Cap 0 .0) o contador do registrador é incrementado, portanto, em um segundo o registrador armazena o valor da freqüência de oscilação do LM555.

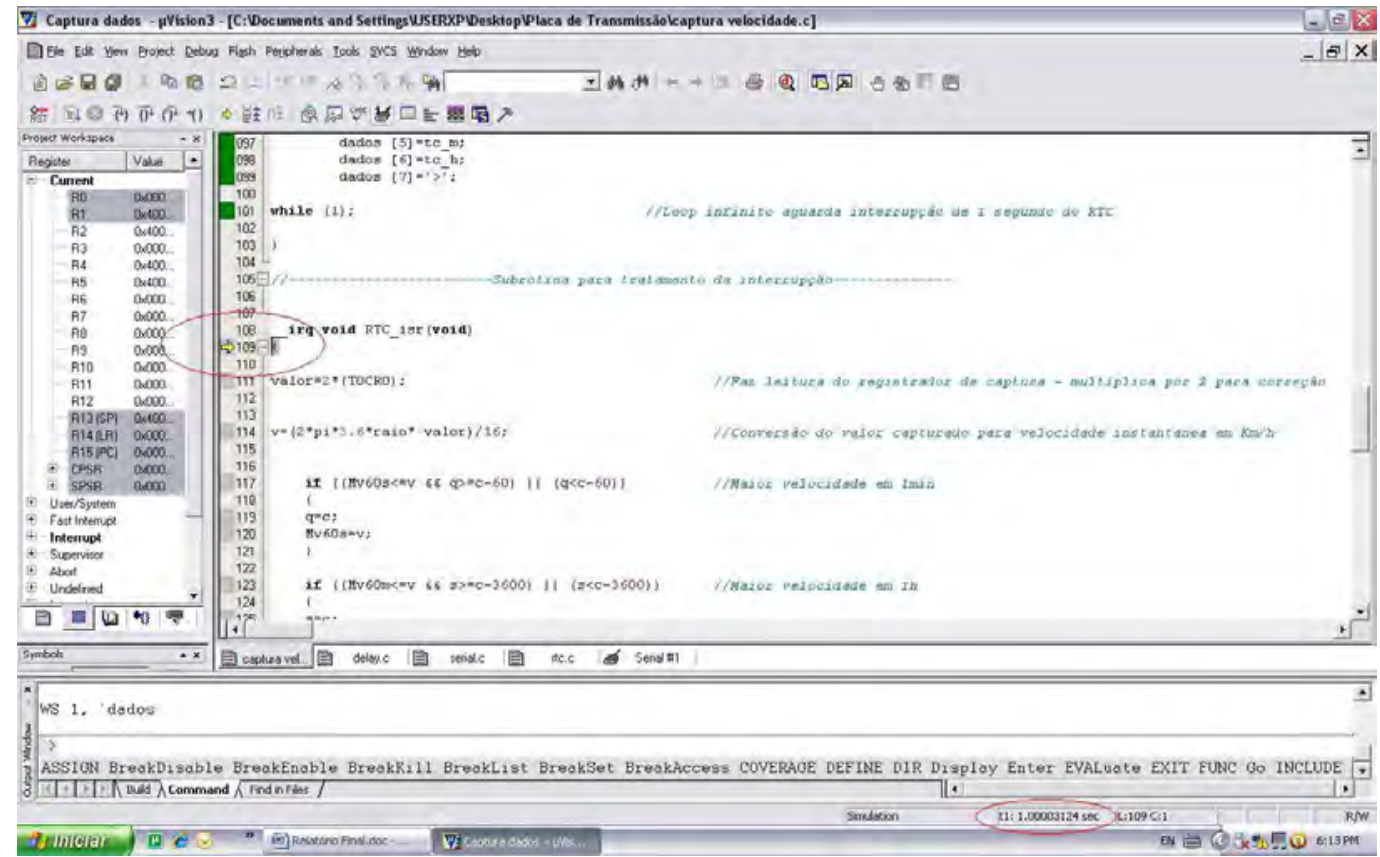

Figura 17. Código exibindo momento de chamada de interrupção do RTC.

Na figura 18 observa-se que a interrupção foi acionada após aproximadamente um segundo, como era de se esperar.

A saída do oscilador LM555 foi visualizada com o auxílio de um osciloscópio, onde pode-se comprovar que o multivibrador monoastável estava funcionando corretamente, dentro a faixa de freqüência desejada.

Para verificar se os cálculos da velocidade e demais dados está correta foi inserido um valor fixo na GPIO configurada como pino de captura. 


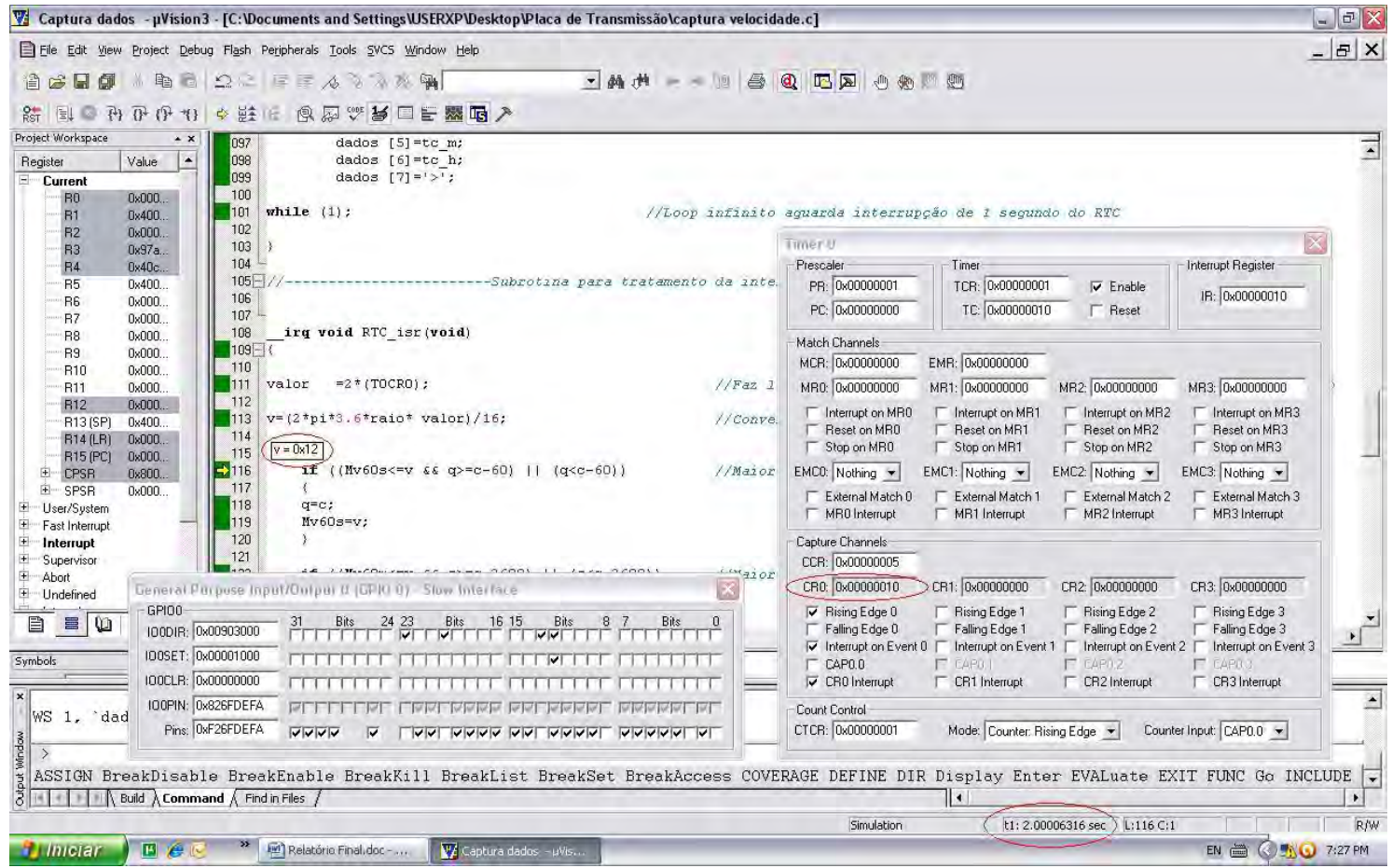

Figura 18. Código com cálculo da velocidade atual para $32 \mathrm{~Hz}$.

Analisando a figura, nota-se que a interrupção ocorreu com dois segundos, foi simulado a oscilação de $32 \mathrm{~Hz}$ através do pino P 0.2 , onde se encontra a saída do LM555. O registrador de captura CR0 armazenou o valor 16 (10 em hexadecimal), pois toda vez que ocorre uma captura o contador do Prescaler (TC) é zerado e como o valor do Prescaler (PR) é 1 a captura não ocorre nesse ciclo, para resolver isso o valor do registrador é multiplicado por 2. Portanto o valor calculado para a velocidade foi $0 \times 12$ (12 em hexadecimal) que convertido fica $18 \mathrm{Km} / \mathrm{h}$.

Fazendo o calculo manualmente o valor obtido foi:

$$
\mathrm{V}=18,9 \mathrm{Km} / \mathrm{h}
$$

A diferença se deve ao fato do programa ignorar as casas decimais, pois toda manipulação dos valores é feita em hexadecimal.

Considerando uma freqüência de $420 \mathrm{~Hz}$, a velocidade calculada deve ser de $248,8 \mathrm{Km} / \mathrm{h}$. Inserindo o valor no registrador de captura, tem-se o seguinte resultado na figura 19: 


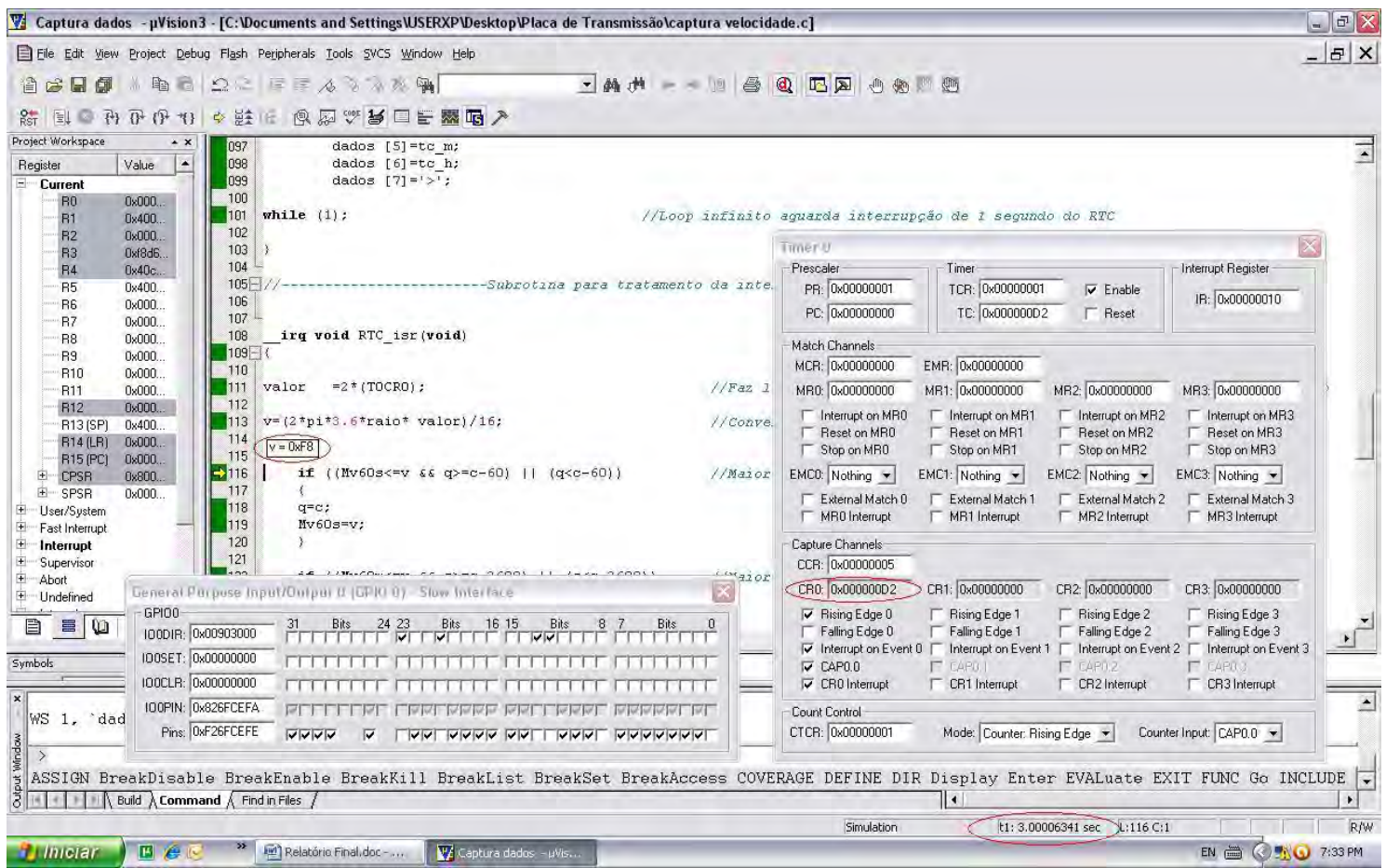

Figura 19. Código com cálculo da velocidade atual para $420 \mathrm{~Hz}$.

Verifica-se o valor $0 x F 8$ que em decimal vale $248 \mathrm{Km} / \mathrm{h}$, dessa forma, mais uma vez obteve-se o valor esperado.

\subsection{Verificando a transmissão dos dados entre as placas}

Para verificação da comunicação entre os dois módulos, foi utilizado o terminal do Flash Magic, assim basta enviar o mesmo vetor enviado à UART1, que está ligada ao módulo XBee, para UART0 que esta ligada ao PC, conforme figura 20.

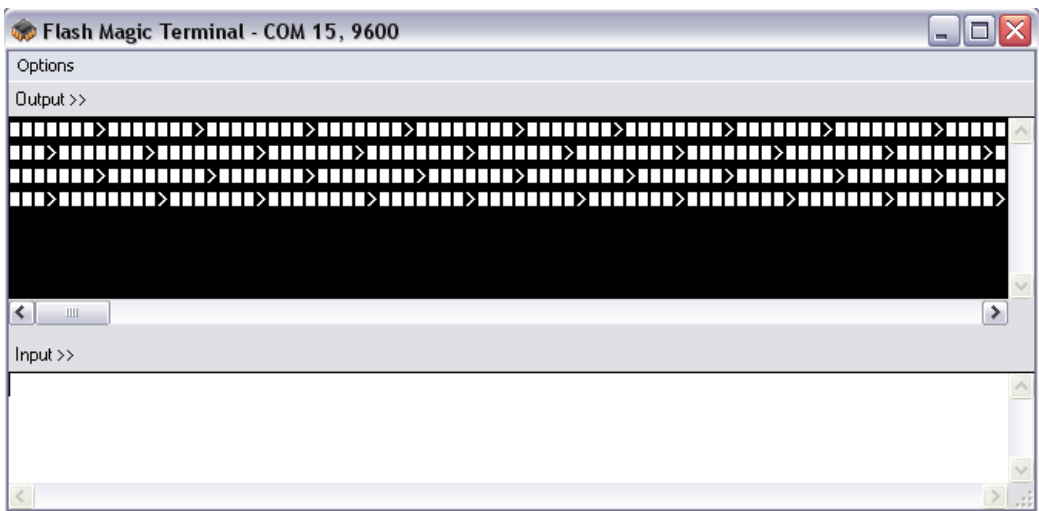

Figura 20. Terminal do Flash Magic exibindo dados enviados à UART0.

Verifica-se que os dados estão sendo enviados à serial 0 , ou seja, os dados estão disponíveis no módulo XBee. Como esperado o vetor tem 7 dados calculados a partir da captura do sensor de velocidade e um bit de parada ('>'). 


\section{CONCLUSÃO}

Os microcontroladores que conseguem aliar baixo consumo com alto desempenho estão ganhando cada vez mais popularidade com o avanço da disseminação de dispositivos portáteis como Notebooks, GPS, Smartfones entre outros.

O projeto desenvolvido abordou alguns dos principais recursos presentes no processador da família ARM, e certamente foi bastante proveitoso todo o desenvolvimento e serviu como base para o desenvolvimento de aplicações mais complexas.

A utilização da comunicação wireless Zigbee também foi importante, visto que é um protocolo que aos poucos vem ganhando espaço tanto em aplicações domésticas quanto industriais devido à sua simplicidade e custo benefício.

O desafio maior foi fazer um programa mais robusto e completo pra realização das tarefas necessárias, a comunicação serial requer alguns cuidados e a manipulação das variáveis envolvidas deve ser bem executada.

A comunicação wireless ZigBee se mostrou eficiente para o projeto proposto, embora esse projeto tenha utilizado uma rede wireless com apenas dois dispositivos, a expansão para uma rede mais complexa é totalmente possível pois o módulo XBee é facilmente configurável através do software X-CTU.

O sistema de comunicação foi realizado apenas em laboratório. Nesta próxima etapa, estamos trabalhando com comunicação bluetooth e tecnologia para Android.

\section{REFERÊNCIAS BIBLIOGRÁFICAS}

[1] de Souza, Daniel Rodrigues; "Microcontroladores ARM7 - Philips família LPC213x - O Poder dos 32 Bits"; Ed. Érica; São Paulo; 1ª Edição; 2006

[2] Schildt, Herbert; “C - Completo e Total”; Ed. Makron Books; São Paulo; 3ª Edição; 1997

[3] da Silva, Bruno Novais; Diniz, Ivando. "Scanner Automotivo Wireless"; trabalho de graduação apresentado à Unesp de Sorocaba; Sorocaba/SP/Brasil; dezembro/2008.

[4] de Aguiar, Felipe Pereira; Diniz, Ivando. "Sistema de Gerenciamento de Diagnóstico Automotivo utilizando padrão OBDII, comunicação wireless e interface PC"; trabalho de graduação apresentado à Unesp de Sorocaba; Sorocaba/SP/Brasil; dezembro/2008.

[5] Zigbee: "Wireless Control That Simply Works". Craig, William C. Program Manager Wireless Communications. ZND America, Inc. , Disponível em:

www.zigbee.org/imwp/idms/popups/pop_download.asp?contentID=5162 -

[6] IEEE 802.15.4 and Zigbee Overview, Dvorak, Joe. Motorola. Disponível em:

www.media.mit.edu/resenv/classes/MAS961/readings/802-15-4_Tutorial.ppt -

[8] "zigbbe" $<$ http://www.digi.com/technology/rf-articles/wireless-zigbee.jsp $>$ Acesso $10 \mathrm{de}$ março de 2018 